\title{
Early Detection of Multivessel Disease and Prevention of Short and Long Term Complications
}

\author{
Dr. Mohammad Aminul Islam ${ }^{1 *}$, Dr. AHK Chowdhury², Dr. AKM Mujibur Rahman ${ }^{3}$, Dr. Md. Khalequzzaman ${ }^{4}$
}

${ }^{1}$ Assistant Professor, Cardiology, National Center for Control of Rheumatic Fever \& Heart Disease, Dhaka, Bangladesh

${ }^{2}$ Professor, Cardiology \& Ex. Director, National Institute of Cardio-Vascular Diseases, Dhaka, Bangladesh

${ }^{3}$ Professor, Medicine \& Ex. Director, Shaheed Suhrawardi Hospital, Dhaka, Bangladesh

${ }^{4}$ Associate Professor, Cardiology, National Institute of Cardio-Vascular Diseases, Dhaka, Bangladesh

DOI: $10.36347 /$ sjams.2020.v08i10.013

| Received: 27.09.2020 | Accepted: 09.10.2020 | Published: 15.10.2020

*Corresponding author: Dr. Mohammad Aminul Islam

Abstract

Original Research Article

Objective: In this study our main goal is to early detection of multivessel disease and prevention of short and long term complications. Methods: This was prospective and observational study conducted at National Institute of Cardiovascular Diseases, Shere-e-Bangla Nagar, Dhaka, Bangladesh from February 2012 to December 2012. We examined enlisted eighty four $(n=84)$ consecutive patients with acute inferior myocardial infarction within 12 hours of onset of chest pain and underwent thrombolysis in coronary care unit. Consequently patients were classified in two groups on the basis of admission electrocardiogram. Group A patients with acute inferior myocardial infarction associated significant $(\geq 0.1 \mathrm{mV})$ precordial ST segment depression in leads $\mathrm{V}_{1}-\mathrm{V}_{6}(\mathrm{n}=44,52.38 \%)$; whereas group B had no remarkable precordial ST segment change $(n=40,47.62 \%)$. Thereafter Echocardiography was recorded within $3^{\text {rd }}$ day and catheterization with coronary angiography was done within 4 weeks of infarction. Result: Angiographic result was in patients with precordial ST depression had more prevalence to double vessel $(77.3 \%$ vs. $22.5 \%)$ and triple vessels disease found to be higher in group A (15.9\% vs. 2.5\%). Though anterior descending artery involvement was higher than left circumflex, but independent left anterior descending lesion could not implicated. Conclusion: In overall outcome, patients with ST segment depression in acute inferior myocardial infarction liked with more wideness of ischemic area of infracted zone and more prevalence to multi vessel lesion (double or triple vessel) and index of worse prediction. In conclusion, the current study may give significant clinical benefit to prediction of coronary artery involve from admission ECG, concurrently it will help to categorize the treatment strategy as which patient need emergency support.

Keywords: Myocardial infarction, ST segment, electrocardiograph, anterior ischemia.

Copyright $(\mathcal{C} 2020$ The Author(s): This is an open-access article distributed under the terms of the Creative Commons Attribution 4.0 International License (CC BY-NC 4.0) which permits unrestricted use, distribution, and reproduction in any medium for non-commercial use provided the original author and source are credited.

\section{INTRODUCTION}

Sudden cardiac arrest and death for cardiac diseases due to acute myocardial infarction is a worldwide prevalent cause. It also a prime reason for morbidity and disability of daily life in post infarction period. Evidence showed that about $30 \%$ of all deaths merit for cardiovascular diseases, among them more than half is account of coronary artery involved diseases (CAD). It is a major health problem in developed countries. But now a days, it also rapid rising question in developing world and close to $80 \%$ of dying from cardiovascular in compare to ameliorated countries.

Concern of precordial ST segment depression in relation with acute inferior myocardial infarction (AIMI) enhances both mortality and morbidity. Noticing from electrocardiograph (ECG), isolated acute ST elevation in II, III, aVF suggested that sign of transmural inferior myocardial infarction with some occasion posterior extension. However, concomitant precordial ST segment depression in anterior chest leads $\mathrm{V}_{1}-\mathrm{V}_{6}$ in conjugation with acute inferior myocardial infarction, evidence suggested of extensive transmural lateral or anterior ischemia. Previous studies have showed that precordial ST segment depression in case of acute inferior myocardial infarction consist of approximately half of acute myocardial infarction. This ST segment depression may due to $1^{\text {st }}$ anterior ischemia owing to left sided coronary artery involvement alongside of inferior infarction, $2^{\text {nd }}$ extension of inferior infarction comprises infero-lateral or postero-lateral wall and $3^{\text {rd }}$ it may be reciprocal change resulting from vasospasm or inflammatory reaction to inferior infarction [1-10]. 
Though, maximum ST segment depression in $\mathrm{V}_{1}-\mathrm{V}_{6}$ is different cause and varied ways of mechanism, resulting LV dysfunction because of diverse appointments. Patient with highest ST depression in $\mathrm{V}_{1^{-}}$ $\mathrm{V}_{3}$ likely engaged posterior or inferoseptal wall extension of acute infarction. On the other hand, greater ST depression in leads $\mathrm{V}_{4}-\mathrm{V}_{6}$ possibly suggests multi coronary artery disease, mostly trend to anterior descending coronary artery involved [11-16].

Recent days, important changes has taken for the management of acute myocardial infarction patients, concept is reperfusion of ischemic myocardium by means of thrombolytic therapy or by invasive procedure like angioplasty with or without coronary stenting. It is fundamental approach to such cases, emphasis provided for rapid restoration of blood flow to jeopardize area and to reduce myocardial cell death. The importance and urgency of reperfusion depends on time onset of heart attack as well as amount of myocardium at risk and identification of high risk subgroups based on ECG criteria.

To investigate the underlying mechanisms of different pattern of ST depression in chest leads $\mathrm{V}_{1^{-}}$ $\mathrm{V}_{6}$ were assessed by Angiographic findings in patients with acute inferior myocardial infarction. ECG is the simplest, inexpensive and noninvasive bedside available test to diagnosis as well as categorizes patients in subgroups and may help to identify patients who have multi vessel coronary artery disease. These kinds of patient are at high risk and therefore may get more benefit from invasive approach. Early aggressive reperfusion therapy is beneficial which significantly reduces the risk of major complications, in-hospital deaths and long term mortality and morbidity. Considering these, much effort has been put into correlating ECG changes in acute ischemic episode with coronary angiogram which is the aim of our current study.

\section{OBJECTIVE \\ General Objective}

- The aim of current study is to early detection of multivessel disease and prevention of short and long term complications.

\section{Specific Objective}

- Determine the relationship between precordial ST segment depression in association with acute inferior myocardial infarction and number of coronary artery stenosis by direct catheterization and coronary angiogram.

- Correlate the reasons of precordial ST segment depression with acute inferior myocardial infarction.

\section{Methodology}

Study type: It was a Prospective and observational study.

Study Place and Period: National Institute of Cardiovascular Diseases, Shere-e-Bangla Nagar, Dhaka, Bangladesh from Feb'2012 to Dec'2012.

Sampling Method: Non-probability purposive sampling method was used to select sample population.

Study Population: Patients with precordial ST segment depression in case of acute inferior myocardial infarction got admission within 12 hours of commencement of chest pain in coronary care unit of above mentioned Hospitals. Every selected patient have got IV streptokinase in CCU and undergone coronary angiogram within 28 days of acute attack.

\section{Selection Criteria Inclusion Criteria}

- Patients admitted with definite diagnosis of Acute Inferior Myocardial Infarction within 12 hours onset of symptoms (WHO criteria).

- Patient with or without precordial ST segment depression was included and all patients got thrombolytic therapy streptokinase IV in Coronary Care Unit (CCU).

- Therefore, subsequent catheterization and coronary angiography was conducted within four weak of acute myocardial infarction.

\section{Exclusion Criteria}

- Acute Myocardial Infarction after PCI (percutaneous coronary invasion) or $\mathrm{CABG}$ (Coronary Artery Bypass Grafting).

- AMI patients admitted after 12 hours of onset of symptoms.

- Previous myocardial infarction.

\section{Procedure and Data Collection}

After patient's admission in coronary care unit, initial evaluation was done by detail history taking, through clinical examination and relevant laboratory investigations. Demographic data like age, sex and risk factors including dyslipidemia, hypertension, diabetes mellitus, family history of heart attack and smoking were noted. All data was recorded in a pre-designed form. The continuous variables were expressed in their mean $( \pm \mathrm{SD})$. The mean difference was compared by unpaired " $t$ " test and / or ANOVA. The categorical data (variables) was presented in percentage or $\mathrm{p}$ ratio. The difference of percentage or $\mathrm{p}$ ratio was compared by chi-square test or Fisher's exact test. The correlation and regression test was done to find out the correlation and predictability of the variables. The results of the study were expressed by different tables, graphs, charts, diagrams etc. in relevant cases. At the end of the study 
Aminul Islam et al., Sch J App Med Sci, October, 2020; 8(10): 2271-2277

data analysis, result, discussion, summery and conclusion of the whole research had presented.

\section{Statistical Analysis}

After collecting the data, statistical analysis was done by using computer-based SPSS (Statistical Package for Social Science) version 12. Continuous data were expressed as mean \pm standard deviation. Dichotomous data were disclosed as percentage. Student's t-test, chi-square test, Fisher's exact test were used as when applicable. $\mathrm{P}$ value of less than 0.05 was considered as statistically significant.

\section{RESULTS}

Enlisted eighty four patients were distributed in two groups- Group A (44 or 52.38\%) patient with acute inferior myocardial infarction accompanied by precordial ST segment deflection in leads $\mathrm{V}_{1}-\mathrm{V}_{6}(\geq 0.1$ $\mathrm{mV}$ ) and Group B (40 or 47.62\%) had no significant precordial ST segment change. Therefore datum were compared and correlated with clinical and angiographic findings between these two groups. Patients with precordial ST segment depression showed more prevalence of multivessel (predominant double vessel \& in some occasion triple vessel disease) coronary artery disease.

\section{Clinical Data Correlation}

There were no significant differences in two groups in respective of diabetes mellitus, smoking and dyslipidemia. According to sex distribution male patients are predominant in both groups (group A $86.4 \%$ vs. $13.6 \%$ \& group B $90 \%$ vs. $10 \%, \mathrm{p}=0.746$ ). Figure of female patients less another cause might be female less careful about their health, only complicated cases are attended to hospital. Male are in ascending may due to male sex hormone, occupation, smoking prevalence.

Table-1: Distribution of patient according to sex:

\begin{tabular}{|l|l|l|l|}
\hline \multirow{2}{*}{ Sex } & Group & p \\
\cline { 2 - 3 } & $\begin{array}{l}\text { Group A (Presence of significance of ST } \\
\text { depression) }\end{array}$ & $\begin{array}{l}\text { Group B (Absence of significance of ST } \\
\text { vepression) }\end{array}$ & \multirow{2}{*}{0.741} \\
\hline Male & $38(86.4)$ & $36(90.0)$ & \\
\hline Female & $6(13.6)$ & $4(10.0)$ & \\
\hline Total & $\mathbf{4 4 ( 1 0 0 . 0 )}$ & $\mathbf{4 0}(\mathbf{1 0 0 . 0})$ & \\
\hline
\end{tabular}

* Fisher's Exact Test was done to measure the level of significance.

Following age distribution in group A had larger number of patients within 51 to 60 years (22 out of 44 and $50.0 \%$ ). It may due to at this age change of vascular connective tissue which reduce vessel wall flexibility result may acts in favor of atherosclerosis.
On the other hand in group B highest number of patients was in between 41 to 50 years (22 out of 40 and $55.0 \%$ ) and statistically it were $50.81 \pm 8.28,48.75 \pm$ 8.68; $\mathrm{p}=0.267$ (Table-2).

Table-2: Distribution of patient according to age

\begin{tabular}{|l|l|l|l|}
\hline \multirow{2}{*}{ Age group } & Group & p \\
\cline { 2 - 3 } & $\begin{array}{l}\text { Group A (Presence of significance of } \\
\text { ST depression) }\end{array}$ & $\begin{array}{l}\text { Group B (Absence of significance of } \\
\text { ST depression) }\end{array}$ & value \\
\hline$<=40$ & $7(15.9)$ & $7(17.5)$ & 0.267 \\
\hline $41-50$ & $13(29.5)$ & $22(55.0)$ & \\
\hline $51-60$ & $22(50.0)$ & $7(17.5)$ & \\
\hline$>=61$ & $2(4.5)$ & $4(10.0)$ & \\
\hline Total & $44(100.0)$ & $40(100.0)$ & \\
\hline Mean \pm SD & $50.81 \pm 8.28$ & $48.75 \pm 8.68$ & \\
\hline
\end{tabular}

$*$ Independent t-test was done to measure the level of significance.

Next to test of occupation had showed no significant variation of coronary atherosclerotic disease between different professionals
Figure within parentheses indicates in percentage. 


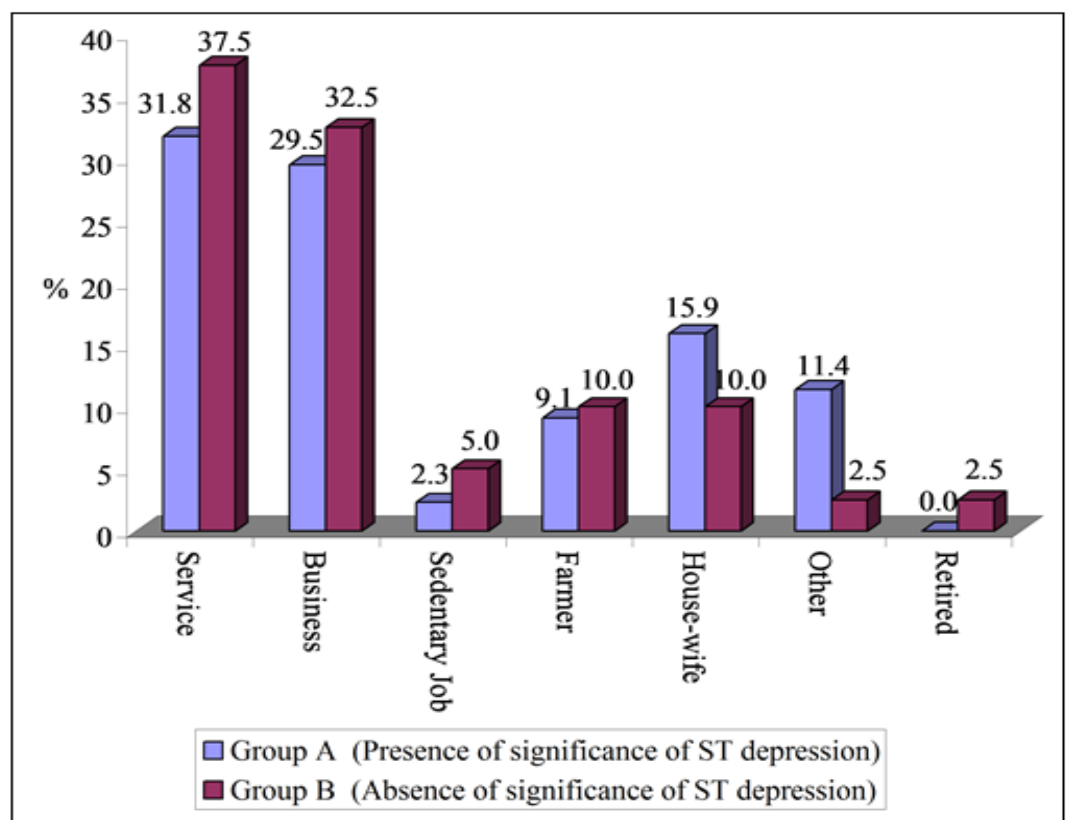

Fig-1: Bar diagram of patient according to occupation

\section{Compared of Echocardiography report:}

Exploration data of Table 4 and 5 delineate the picture of Echocardiographic figures. It shows inferior myocardium motion abnormality is common for both group. Additionally group A patients have more wide area of ischemia \& both LVIDd $(50.86 \pm 2.98$ vs. 48.12 $\pm 2.86 ; 0.252)$, LVIDs ( $34.06 \pm 5.46$ vs. $32.35 \pm 4.32$; $0.795)$ greater than that of patients in group B. Ejection fraction $(\mathrm{EF} \%)$ was depressed in group A than group B
$(50.47 \pm 4.18$ vs. $55.25 \pm 4.32 ; 0.001)$ which indicate left ventricular systolic function is poor in patients with precordial ST segment depression. Patients with lateral or posterior extension displayed infero-lateral and or inferoseptal wall motion abnormality, whereas ST depression in leads $\mathrm{V}_{4}-\mathrm{V}_{6}$ more prone to anteroseptal or anterolateral wall contraction defect $(59.1 \%$ vs. $2.5 \% ; \mathrm{p}=0.001)$.

Table-3: Distribution of patient according to echocardiographic findings

\begin{tabular}{|l|l|l|l|}
\hline \multirow{2}{*}{$\begin{array}{l}\text { Echocardiographic } \\
\text { findings }\end{array}$} & Group & p \\
\cline { 2 - 4 } & $\begin{array}{l}\text { Group A (Presence of significance } \\
\text { of ST depression) }\end{array}$ & $\begin{array}{l}\text { Group B (Absence of significance } \\
\text { of ST depression) }\end{array}$ & value \\
\hline LV EF (\%) & $50.47 \pm 4.18$ & $55.25 \pm 4.32$ & 0.001 \\
\hline LV IDd (mm) & $50.86 \pm 2.98$ & $48.12 \pm 2.864$ & 0.252 \\
\hline LV IDs (mm) & $34.06 \pm 5.46$ & $32.35 \pm 4.32$ & 0.795 \\
\hline
\end{tabular}

*Independent t- test was done to measure the level of significance.

Data were analyzed with using Student t-Test and presented as mean \pm SD

Table-4: Distribution of patient according to number of diseased coronary vessel: Group A majority patients got multivessel disease and group B highest number of patients with single artery block

\begin{tabular}{|l|l|l|l|}
\hline \multirow{2}{*}{$\begin{array}{l}\text { Diseased coronary } \\
\text { vessel }\end{array}$} & $\begin{array}{l}\text { Group } \\
\text { Group A (Presence of significance of } \\
\text { ST depression) }\end{array}$ & $\begin{array}{l}\text { Group B (Absence of significance of } \\
\text { ST depression) }\end{array}$ & $\begin{array}{l}\text { p } \\
\text { value }\end{array}$ \\
\hline Single vessel & $3(6.8)$ & $30(75.0)$ & 0.001 \\
\hline Double Vessel & $34(77.3)$ & $9(22.5)$ & \\
\hline Triple Vessel & $7(15.9)$ & $1(2.5)$ & \\
\hline Total & $\mathbf{4 4 ( 1 0 0 . 0 )}$ & $\mathbf{4 0}(\mathbf{1 0 0 . 0})$ & \\
\hline \multicolumn{2}{|l|}{$*$ Chi-square test was done to measure the level of significance. }
\end{tabular}
$\left(\mathrm{X}^{2}\right)$ Test

Figure-2 Bar diagram of patient according to number of diseased coronary vessel: Data was analyzed by using Chi-square 


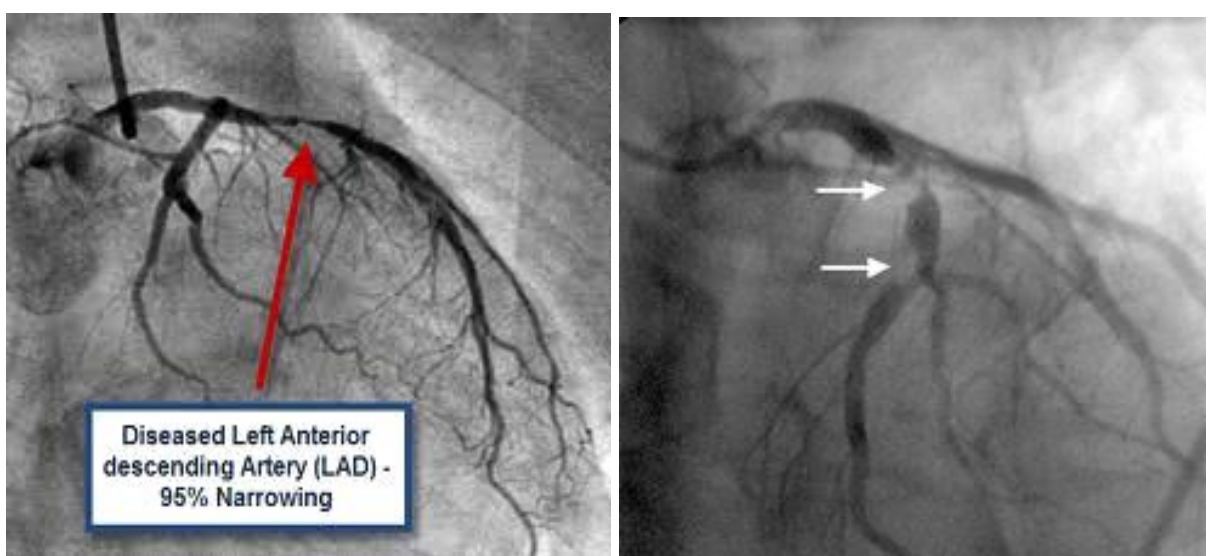

Fig-2: Angiographic image with red arrow displayed proximal left anterior descending artery stenosis and $2^{\text {nd }}$ one with left circumflex artery disease proximal and at $\mathrm{OM}_{1}$ brnch

Individual group study displayed that in group A patients have thirty one LAD, twenty one with LCX and thirty eight got RCA lesion $(70.45 \%, 47.73 \%$ \& $86.36 \%$ respectively). In group B five patients LAD, five in LCX \& thirty seven had RCA out of 40 patients $(12.5 \%, 12.5 \%$ \& $92.5 \%$ respectively). Group A patients have got double artery disease in nineteen (43.18\%) RCA plus LAD, three $(6.8 \%)$ LAD plus LCX, eleven $(25 \%)$ patients with RCA plus LCX stenosis, and only one patient got RCA with D1 coronary block. Three patients with single LCX (6.8\%) stenosis in group A. Number of triple coronary artery disease in group A was 7 (15.9\%). In contrast group B displayed large-scale thirty patients $(75 \%)$ of single vessel stenosis than that of group A patients (75\% vs. $2.38 \%$, $\mathrm{p}=0.0000)$. Only one patients in group A had triple vessel disease $(3.03 \%$ vs. $16.673 \%, \mathrm{p}=0339)$.

Group A patients with RCA lesion revealed seventeen proximal, fourteen mid and rest seven distal RCA block. In group B, proximal RCA stenosis were sixteen $(47.1 \%)$ and fourteen patients with mid RCA occlusion (41.2\%). Remaining four of 38 got distal RCA lesion.

Table-5: Types of lesions in different coronary arteries among the study patients:

\begin{tabular}{|c|l|l|l|}
\hline Coronary vessels involved & Group & \multirow{2}{*}{ p value } \\
\cline { 2 - 3 } & $\begin{array}{l}\text { Group A (Presence of } \\
\text { significance of ST depression) }\end{array}$ & $\begin{array}{l}\text { Group B (Absence of significance } \\
\text { of ST depression) }\end{array}$ & \\
\hline LMCA (Concentric) & $\mathbf{0}(\mathbf{0 . 0})$ & $\mathbf{0}(\mathbf{0 . 0})$ & $\mathbf{0 . 7 7 1}$ \\
\hline LAD & $31(100.0)$ & $5(100.0)$ & \\
\hline Concentric & $22(70.96)$ & $4(80.0)$ & \\
\hline Eccentric & $7(22.6)$ & $0(14.3)$ & \\
\hline Multiple irregularities & $2(6.45)$ & $1(20.0)$ & $\mathbf{0}(\mathbf{0 . 0})$ \\
\hline Diagonal branch (Concentric) & $\mathbf{1 ( 1 0 0 . 0 )}$ & $\mathbf{5}(\mathbf{1 0 0 . 0})$ & $\mathbf{0 . 8 2 7}$ \\
\hline LCX & $\mathbf{2 1 ( 1 0 0 . 0 )}$ & $3(60.0)$ & \\
\hline Concentric & $15(71.4)$ & $1(20.0)$ & \\
\hline Eccentric & $5(23.8)$ & $1(20.0)$ & \\
\hline Multiple irregularities & $1(4.76)$ & $\mathbf{1}(\mathbf{1 0 0 . 0})$ & $\mathbf{0 . 5 0 0}$ \\
\hline Marginal (Concentric) & $\mathbf{1 ( 1 0 0 . 0 )}$ & $\mathbf{3 7}(\mathbf{1 0 0 . 0})$ & \\
\hline RCA & $\mathbf{3 8 ( 1 0 0 . 0 )}$ & $22(59.5)$ & \\
\hline Concentric & $26(68.42)$ & $13(35.1)$ & \\
\hline Eccentric & $9(23.68)$ & $2(5.4)$ & \\
\hline Multiple irregularities & $3(7.89)$ & & \\
\hline
\end{tabular}

*Chi-square test was done to measure the level of significance.*Figure within parentheses indicates in percentage.

\section{Discussion}

Though it has been debated for long time, however from various studies it is well established that meaningful precordial ST segments depression in association with acute inferior myocardial infarction having worse prognosis and greater mortality and morbidity and manifestation of more than one vessel coronary artery disease. Therefore it accepted that precordial ST segment depression has more chance to have multivessel coronary artery stenosis [17, 18]. Some researchers predicted with precordial ST segment depression independent to left anterior descending artery disease, contrast due to extension of infarction size or ischemic zone. James H. S. Cullen et al., found that patients with precordial ST segment depression had larger perfusion deficits in postero-laterally than non ST segment depressant patients and there was significant increase in number of adverse clinical end points with 
Aminul Islam et al., Sch J App Med Sci, October, 2020; 8(10): 2271-2277

global perfusion abnormality. Whereas Shah et al. suggested that either anterior or posterior ischemia produces this electrocardiographic diversity. Roubin et al., examined anatomy of coronary artery and anterolateral ST segment depression during acute inferior myocardial infarction and they reported more prevalence to have two or three coronary artery disease in case of precordial ST segment depression $[18,19]$.

In our study findings based on coronary angiography has supported investigation of Jennings et al., who found anterior chest lead ST segment depression during acute inferior myocardial infarction due to additional artery involved [20]. We also found patients with precordial ST segment depression higher prevalence of more than one coronary artery disease. Our result shows patients with precordial ST segment depressions has got superior number of left anterior descending artery stenosis $(70 \%)$ and lower than LAD but a great number of left circumflex artery (47\%) disease. Maximum of double vessel $(77.3 \%)$ disease right coronary with left anterior descending or right coronary plus left circumflex and some are left circumflex with left anterior descending artery.

Among all patients, one from Group B patient found to have no significant epicardial coronary artery disease with normal CAG findings. This patient was thrombolysis within one hour of onset of Myocardial Infarction; cause might get complete dissolution of clot and complete recanalization.

$\mathrm{RV}$ infarction is most frequent with proximal RCA occlusion and complicates approximately $20 \%$ of all Myocardial Infarction and up to $50 \%$ in Acute Inferior Myocardial Infarction. Existence study revealed right ventricular infarction in six (13\%) patients of group A and nine $(22.5 \%)$ of group B. RV infarction very closely related with right coronary artery causing infarction and almost all culprit lesion found proximal to all major RV branch. Ongoing study is consistent with those of previous documented report in association with RCA lesion before or after RV branch and right ventricular dysfunction.

All proximal right coronary artery lesions did not get right ventricular (RV) infarction, because it is thought to be less myocardial $\mathrm{O}_{2}$ demand of Right Ventricle, comparatively thinner wall of RV or greater diastolic flow ratio in coronary vessel perfusion. It also thought that increased ability to consume more $\mathrm{O}_{2}$ during stressful condition. In some cases presence of extensive collateral vessels to protect Right Ventricle from Ischemic damage. Some studies reported that ST segment elevation in right sided ECG during acute inferior myocardial inflation due to transient stress extension which correlates with duration of ischemia [21]. Diagnosis of Right Ventricular infarction on the basis of ST segment elevation in $\mathrm{V}_{4} \mathrm{R}$, it's specificity $78 \%$, sensitivity $88 \%$ and diagnostic efficiency about
$83 \%$ [20]. During acute inferior infarction changes STsegments in leads of RV infracted wall and infarction of inferior or postero-lateral wall are opposite influence. In case of RV Infarction, ST segment tends to elevate whereas in case of inferior or infero-lateral infarction express reciprocal ST segment depression.

Following sex distinction male were $86.4 \%$ and female $13.6 \%$ in Group A, similarly male $90 \%$ and female $10 \%$ in Group B out of total eighty four study populations with male: female ratio were 10:1. Overall female are lower incidence of myocardial infarction is due to mainly female hormone estrogen which is established by various studies. Premenopausal women have low atherogenic complications. But this picture turns dramatically to develop coronary atherosclerosis with ischemic episode in post-menopausal period. Among other causes female is less careful about won health, poverty, ignorance in family, less habit of smoking.

Comparison of risk factors for coronary artery stenosis current study showed that most prevalence was smoking $70.5 \%$ vs. $75.5 \%$ followed by hypertension $47.7 \%$ vs. $32.5 \%$, next of diabetes mellitus $43.2 \%$ vs. $35.0 \%$, dyslipidemias $25 \%$ vs $17.5 \%$ and family history $4.5 \%$ vs. $2.5 \%$ of heart attack.

Time of hospital attendance and onset of pain were average six hours. Among them only $30 \%$ were able to attend in hospital emergency department before 5 hours of onset chest pain.

Cardiac marker Troponin-I was higher in those who reached hospital before 5 hours of onset of chest pain and it upraised in case of associated precordial ST segment depression, in group A $34.25 \pm 18.35 \mathrm{ng} / \mathrm{ml}$ and in Group B $30.86 \pm 7.21 \mathrm{ng} / \mathrm{ml}(p=0.721)$. This indicates patients with precordial ST segment depression having larger area of myocardial infarction or more extended field of ischemia. Previous studies also revealed that inferior MI with anterior ST segment depression having wide myocardial ischemia expanded towards infero-lateral or anterior myocardium [22]. Another cardiac specific enzyme which is found in blood early of acute myocardial injury CK-MB (creatine phosphokinase $\mathrm{MB}$ ) also revealed greater value in case of acute inferior myocardial infarction plus precordial ST segment depression in group A $(117.25 \pm 40.49$ vs. $97.65 \pm 7.06, p=0.012)$ which is additional marker of more severe myocardial damage and or further propagation of infarction or ischemia.

\section{CONCLUSION}

From this study it was concluded that it was correlated patients of acute inferior myocardial infarction on basis of hospital arrival ECG with precordial ST segment depression present or absent. Following admission after certain day's coronary 
angiogram was performed and examined number of coronary artery disease.

\section{REFERENCES}

1. Anderson RN. United States Life Tables: Eliminating Certain Causes of Death. Hyattsville, MD. National Centre for Health Statistics, 1999.

2. Shah PK, Pichler M, Berman DS.Noninvasive Identification of a high-risk subset of patients with Acute Inferior Myocardial Infarction. Am J Cardiol. 1980; 46:915-921.

3. Bangladesh Bureau of Statistics: Health, Family planning and Social Statistics, cat no 13 20; BBS, Dhaka, 2007.

4. Willems JL, Willems RJ, Willems GM, Arnold AER, Van de Werf F, Verstraete $M$. Significance of Initial ST- segment elevation and depression for the management of thrombolytic therapy in Acute Myocardial Infarction. Circulation. 1990; 82:1147-1158.

5. Peterson ED, Hathway WR, Zabel KM. Prognostic Significance of Precordial ST-segment depression during Inferior Myocardial Infarction in thrombolytic era: result in 16,52 patients. J Am CollCardiol. 1996; 28:305-312.

6. Yalçin MR, Gençosmanoğlu O, Özduran V, Boyaci B, Çengel A, Dörtlemez Ö, Dörtlemez H. Reciprocal Changes in Acute Inferior Myocardial Infarction: Coronary Angiographic Results of Patients Treated by Thrombolysis. Gazi Medical Journal. 1998;9(3):125-128.

7. Cohen M, Blanke H, Karsh KR, Holt J, Rentrop P. Implications of precordial ST segment during acute inferior myocardial infarction: Arteriographic and Ventriculographic correlations during the acute phase. Br Heart J. 1984; 52: 497501.

8. Chaitman BR, Waters DD, Corbara F, Bourassa MG. Prediction of multivessel Disease after Inferior Myocardial Infarction. Circulation. 1978; 57:1085-190.

9. Birnbaum Y, Wagner GS, Barbash GI, Gates K, Criger DA, Sclarovsky S, Siegel RJ, Granger CB, Reiner JS, Ross AM. Correlation of angiographic findings and right (V1 to V3) versus left (V4 to V6) precordial ST-segment depression in inferior wall acute myocardial infarction. The American journal of cardiology. 1999 Jan 15;83(2):143-8.

10. Acute Coronary Syndrome: Guide line for Management. Bangladesh Cardiac Society, Dhaka, Bangladesh, 2004.

11. Gibson RS, Crampton RS, Watson DD. Precordial ST-segment depression during Acute Inferior Myocardial Infarction: Clinical, Scintigraphic and Angiographic correlations. Circulation. 1982; 66: 732-741.
12. Salcedo JR, Baird MG, Chambers RJ, Beanlands DS. Significance of reciprocal STsegment depression in Anterior Precordial leads in acute inferior Myocardial Infarction concomitant Left Anterior Descending Coronary Artery Disease. Am J Cardiol. 1981: 48: 1003-1008.

13. Parale GP, Kulkarni PM, Khade SK, Athawale S, Vora A. Importance of Reciprocal leads in Acute Myocardial Infarction. The Journal of the Association of Physician of India. 2004; 52: 376-9.

14. Hasdai D, Sclarovsky S, Solodky A, Sulkes J, Strasberg B, Birnbaum Y. Prognostic significance of maximal precordial ST-segment depression in right (V1 to V3) versus left (V4 to V6) leads in patients with inferior wall acute myocardial infarction. Am J cardiol. 1994; 74: 1081-1084.

15. Goldberg HL, Borer JS, Jacobstein JG, Kluger J, Scheidt SS, Alonso DR. Anterior ST segment depression in Acute Myocardial Infarction; Indicator of Posterolateral Infarction, Am J Cardiol. 1981; 48:1009-1015.

16. Cullen JH, Cherryman GR, Samani NJ, Tranter J, Jivan A, Horsfield MA, Woods KL, Barnett DB. Mechanism and clinical significance of precordial ST depression in inferior myocardial infarction: evaluation by contrast-enhanced dynamic myocardial perfusion magnetic resonance imaging. Journal of Cardiovascular Magnetic Resonance. 1999 Jan 1;1(2):121-30.

17. Ong L, Valdellon B, Coromilas J, Brody R, Reiser P, Morrison J. Precordial S-T segment depression in Inferior MI: Evaluation by quantitative Thallium-201 Scintigraphy and Technetium-99 Ventriculography. Am J Cardiol. 1983; 51:734739.

18. Gelman JS, Saltrops A. Precordial ST depression in patients with Inferior Infarction: Clinical implications. Br Heart J. 1982; 8: 560-565.

19. Jennings K, Reid DS, Julian DG. " Reciprocal" depression of the ST segment in acute myocardial infarction. Br Med J (Clin Res Ed). 1983 Sep 3;287(6393):634-7.

20. Little WC, Rogers EW, Sodums MT. Mechanism of anterior ST segment depression during acute inferior myocardial infarction: observations during coronary thrombolysis. Annals of internal medicine. 1984 Feb 1;100(2):226-9.

21. Roubin GS, Shen WF, Nicholson M, Dunn RF, Kelly DT, Harris PJ. Anterolateral ST-segment depression in Acute Inferior Myocardial Infarction: Angiographic and Clinical Implications. Am Heart J. 1984; 107:1177- 1182.

22. Haraphongse M, Jugdutt BI, Rossalla RE. Significance of Precordial ST-segment depression in Acute Inferior Myocardial Infarction: Coronary Angiographic Findings. Catheter based Cardiovascular Diagnosis. 1983; 9: 143-151. 